Maria de Lourdes Martins Alves de Sousa Mestranda no programa de pós-graduação em Ambiente Construído e Patrimônio

Sustentável, Escola de Arquitetura.

Universidade Federal de Minas Gerais Belo Horizonte, Brasil

https://orcid.org/0000-0002-01 49-6365

lu.sousa@yahoo.com.br

Flávio de Lemos Carsalade Professor Titular, Escola de Arquitetura. Universidade Federal de Minas Gerais Belo

Horizonte, Brasil

https://orcid.org/0000-0002-0729-4270

flavio.carsalade@gmail.com

Rogério Palhares Zschaber de Araújo

Professor Associado, Escola de Arquitetura. Universidade Federal de Minas Gerais Belo Horizonte , Brasil https://orcid.org/0000-0003-2965-6372 rogeriopalharesaraujo@gmail.com

\section{O RECONHECIMENTO DOS VALORES PATRIMONIAIS PELA COMUNIDADE E O CONJUNTO MODERNO DA PAMPULHA}

\author{
EL RECONOCIMIENTO DE LOS VALORES \\ PATRIMONIALES POR LA COMUNIDAD Y EL \\ CONJUNTO MODERNO DE PAMPULHA
}
THE RECOGNITION OF HERITAGE VALUES BY THE COMMUNITY AND THE PAMPULHA MODERN ENSEMBLE

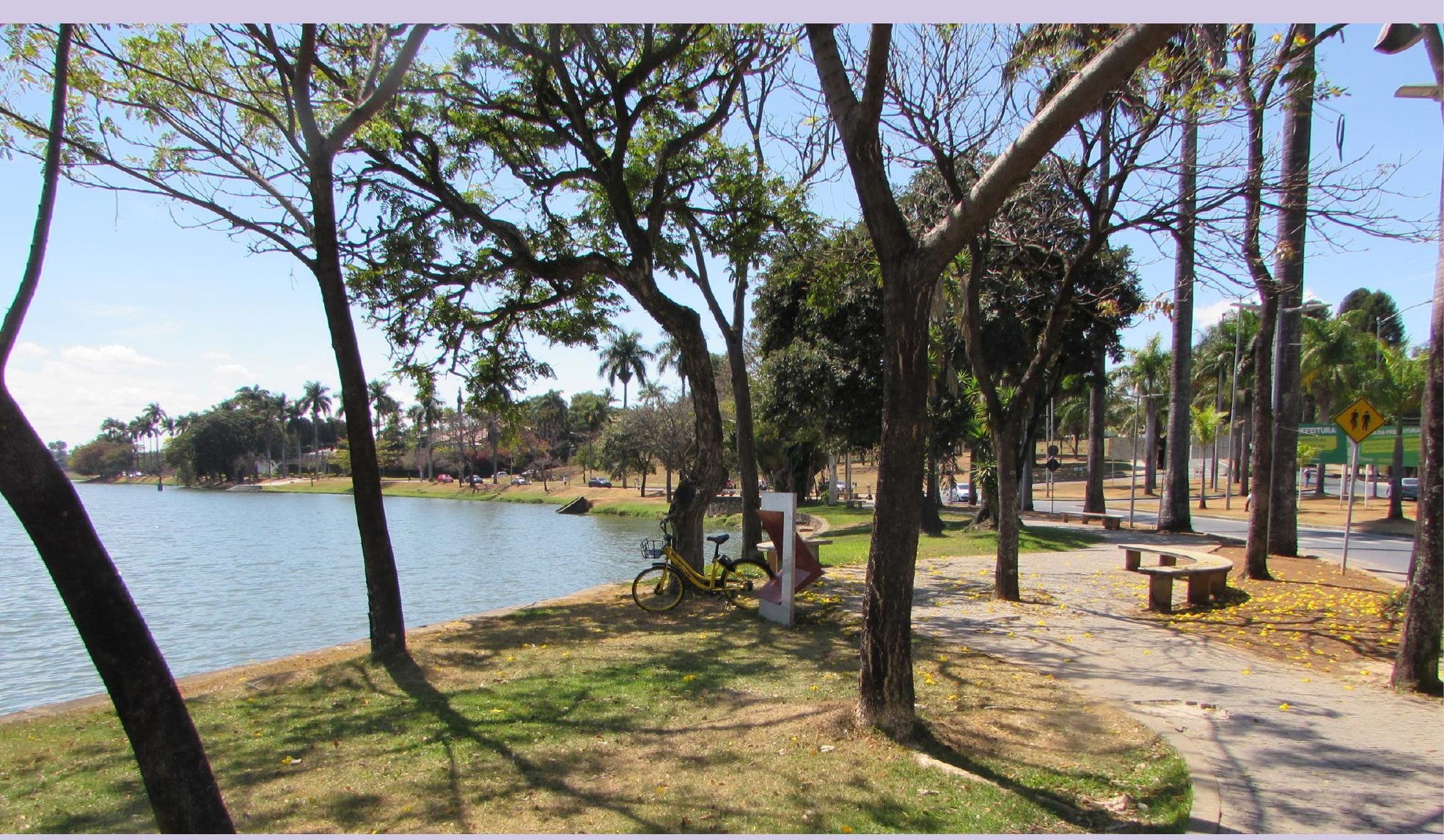

Figura 0 Orla da lagoa da Pampulha. Fonte: Acervo dos autores, 2019.
"CAPES - Coordenação de Aperfeiçoamento de Pessoal de Nível Superior (88887.595811/2020-00) Agradecimento à CAPES pelo apoio ao desenvolvimento desta pesquisa com a concessão de bolsa de mestrado no Programa de PósGraduação em Ambiente Construído e Patrimônio Sustentável." 


\section{RESUMO}

O Conjunto Moderno da Pampulha é um complexo urbano situado em Belo Horizonte, Brasil, cujo contexto metropolitano apresenta grande complexidade em função de pressões da dinâmica urbana, de impactos ambientais da urbanização e da necessidade de gerir mudanças, preservando os atributos da arquitetura e da paisagem que propiciaram o seu reconhecimento como Patrimônio Mundial. Este artigo é parte de um estudo maior que investiga o reconhecimento pela comunidade dos valores conferidos pelos especialistas à paisagem cultural do Conjunto como patrimônio mundial. Devido às condições restritivas impostas pela pandemia da COVID 19, utilizou-se como instrumento para a pesquisa de campo um questionário online de acesso franqueado ao público em geral para a coleta de dados primários junto à comunidade. A análise das respostas obtidas no pré-teste do questionário, objeto deste artigo, demonstram o reconhecimento de elementos da paisagem e do Conjunto Moderno da Pampulha que contribuem para sua fruição e que o caracteriza como paisagem diferenciada no contexto da cidade.

Palavras-chave: arquitetura moderna, gestão participativa, patrimônio cultural, paisagem urbana, Conjunto Moderno da Pampulha.

\section{RESUMEN}

El Conjunto Moderno da Pampulha es un complejo urbano ubicado en Belo Horizonte, Brasil, cuyo contexto metropolitano es altamente problemático debido a las presiones de la dinámica urbana, impactos ambientales de la urbanización y la necesidad de gestionar los cambios y preservar los atributos de la arquitectura y el paisaje que brindaron su reconocimiento como Patrimonio de la Humanidad. Este artículo es parte de un estudio más amplio que investiga el reconocimiento de la comunidad de los valores conferidos por los especialistas al paisaje cultural del Complejo como patrimonio de la humanidad. Debido a las condiciones restrictivas impuestas por la pandemia de COVID 19 , se utilizó un cuestionario en línea con acceso abierto al público en general como instrumento para la investigación de campo para recopilar datos primarios de la comunidad. El análisis de las respuestas obtenidas en el pre-test del cuestionario, objeto de este artículo, demuestra el reconocimiento de elementos del paisaje y del Conjunto Moderno da Pampulha que contribuyen a su disfrute, $y$ que lo caracterizan como un paisaje diferenciado en el contexto de la ciudad.

Palabras clave: arquitectura moderna, gestión participativa, patrimonio cultural, paisaje urbano, Conjunto Moderno da Pampulha.

\section{ABSTRACT}

The Pampulha Modern Ensemble is an urban complex located in Belo Horizonte, Brazil, whose metropolitan context is highly problematic due to the pressures of urban dynamics, impacts from urban development and the need to manage changes and preserve architectural and landscape attributes that have led to its recognition as World Heritage. This article is part of a larger study that investigates the community's recognition of the values conferred by experts on that complex's cultural landscape as a world heritage site. Due to the restrictive conditions imposed by the COVID 19 pandemic, an online questionnaire with open access to the general public was used as an instrument for the field research to collect primary data from the community. The analysis of the answers obtained from the questionnaire pre-test, object of this article, demonstrates the recognition of landscape elements and of the Pampulha Modern Ensemble that contribute to its enjoyment and that characterize it as a differentiated landscape in the context of the city.

Keywords: modern architecture, participatory management, cultural heritage, urban landscape, Pampulha Modern Ensemble. 
Figura 1 Conjunto Moderno da Pampulha. Fonte: Práxis Projetos e Consultoria, 2016, Dossiê (IPHAN, 2017).

\section{INTRODUÇÃO}

1 Organização para a Educação, a Ciência e a Cultura das Nações Unidas.

2 HUL é a abreviatura da terminologia em língua inglesa, Historic Urban Landscape.

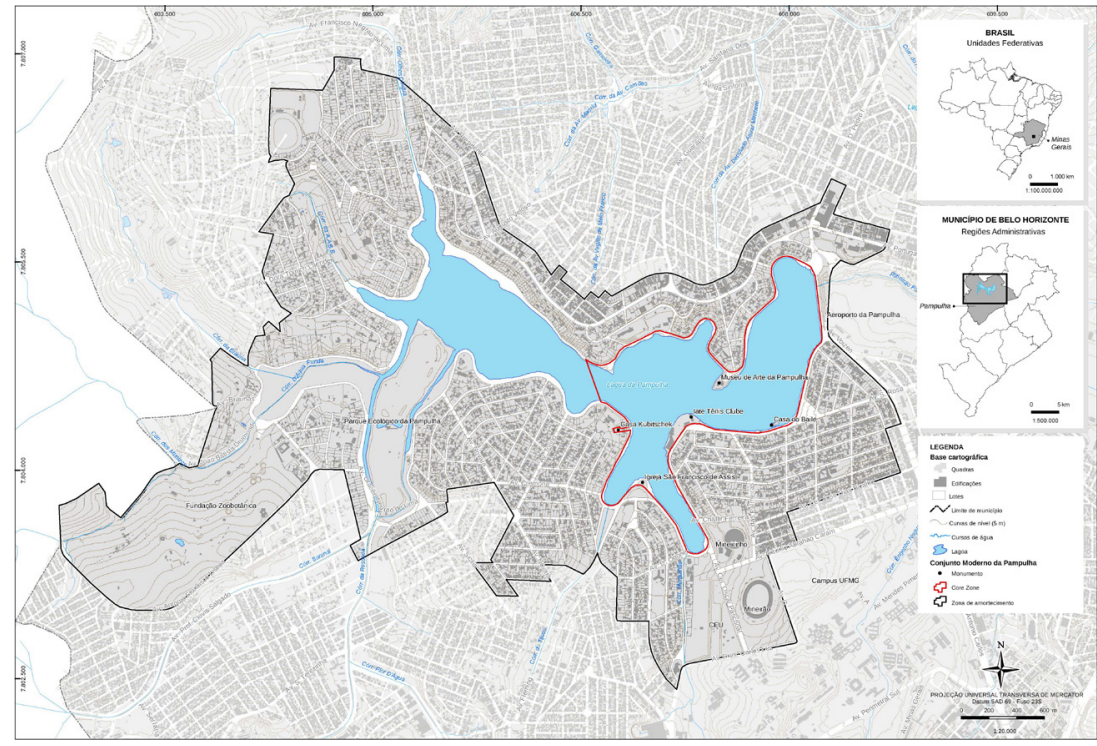

A pesquisa toma como objeto empírico o Conjunto Moderno da Pampulha (Figura I) com foco na recomendação da gestão participativa para aperfeiçoamento das ações previstas no respectivo Plano de Gestão e Monitoramento apresentado no Dossiê de Candidatura a Patrimônio Mundial (IPHAN, 2017). A atribuição do título de patrimônio mundial na categoria de paisagem cultural para o Conjunto Moderno da Pampulha foi baseada no valor universal excepcional (VUE) e nos atributos que integram a arquitetura e a paisagem do local. $O$ presente estudo é inédito e contribui para o atendimento de uma demanda real da UNESCO ', prevista no Plano de Gestão e Monitoramento do Conjunto, de retomar o diálogo com os diversos grupos de interesse presentes na área para o balizamento das ações previstas e aferição das diretrizes de proteção do bem.

Para fundamentar a investigação, partiu-se da revisão bibliográfica sobre paisagem cultural, particularmente sobre a abordagem da Paisagem Urbana Histórica (abordagem HUL) ${ }^{2}$ e da análise de dados e informações secundárias produzidas pelos principais documentos técnicos que compuseram o processo de candidatura do Conjunto Moderno da Pampulha a patrimônio mundial. A pesquisa contribui para o debate sobre formas mais eficazes e integradas de gestão e monitoramento de sítios urbanos históricos, incluindo o envolvimento da comunidade, como sugere a abordagem HUL.

\section{Conjunto Moderno da Pampulha}

O Conjunto Moderno da Pampulha foi criado na década de 1940 em Belo Horizonte, Brasil, a partir de cinco edifícios projetados pelo arquiteto Oscar Niemeyer: a lgreja de São Francisco de Assis, o Cassino (atual Museu de Arte da Pampulha), a Casa do Baile (atual Centro de Referência em Urbanismo, Arquitetura e Design de Belo Horizonte), o late Tênis Clube e um hotel (que não chegou a ser construído), integrados pelo espelho d'água e pela orla do lago artificial, seus respectivos jardins, de autoria do paisagista Roberto Burle Marx, e suas obras de artistas modernistas integradas aos edifícios (Figuras 2, 


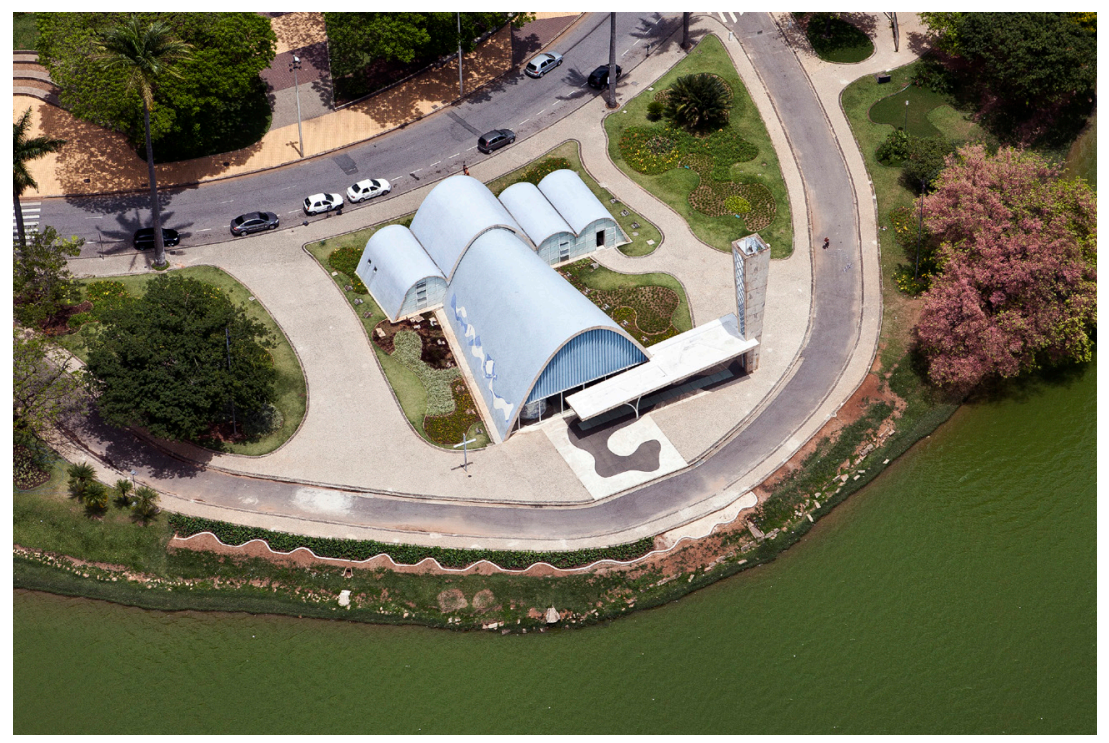

Figura 2 Igreja São Francisco de Assis. Fonte: Marcílio Gazzinelli.

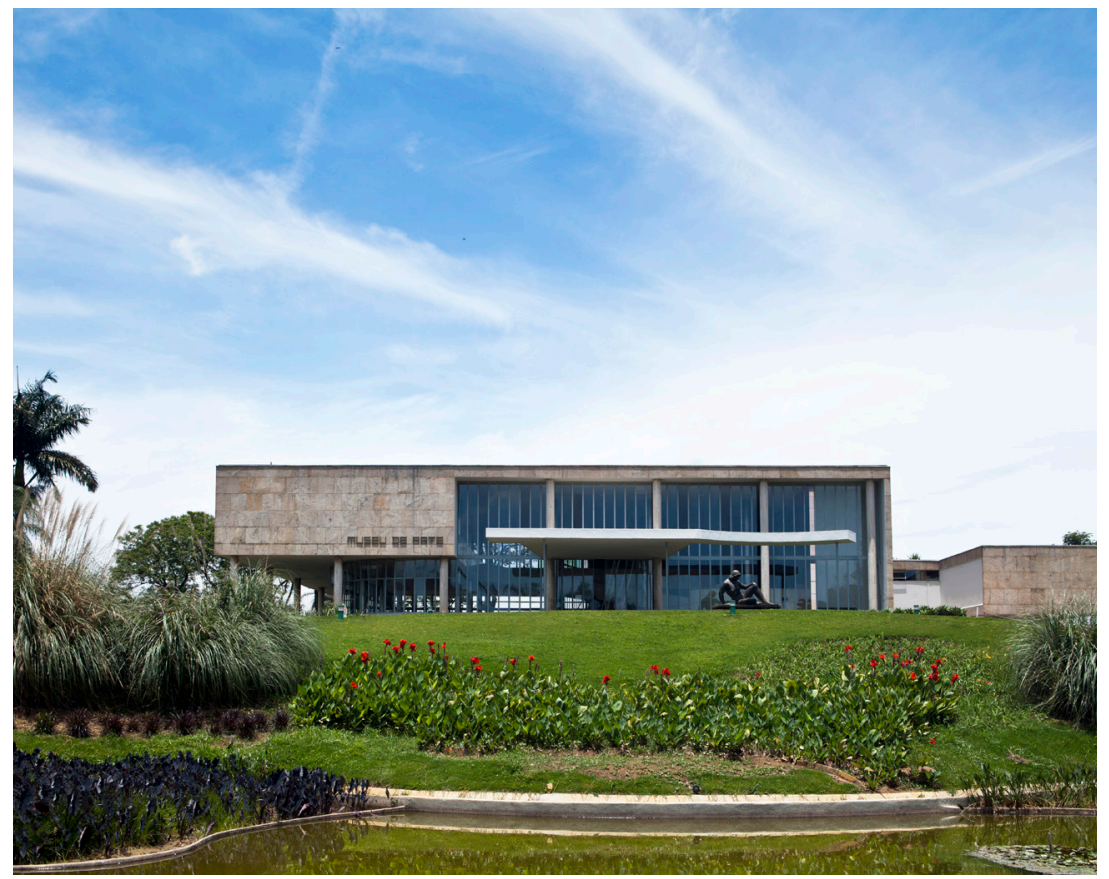

Figura 3 Museu de Arte da Pampulha. Fonte: Marcílio Gazzinelli.

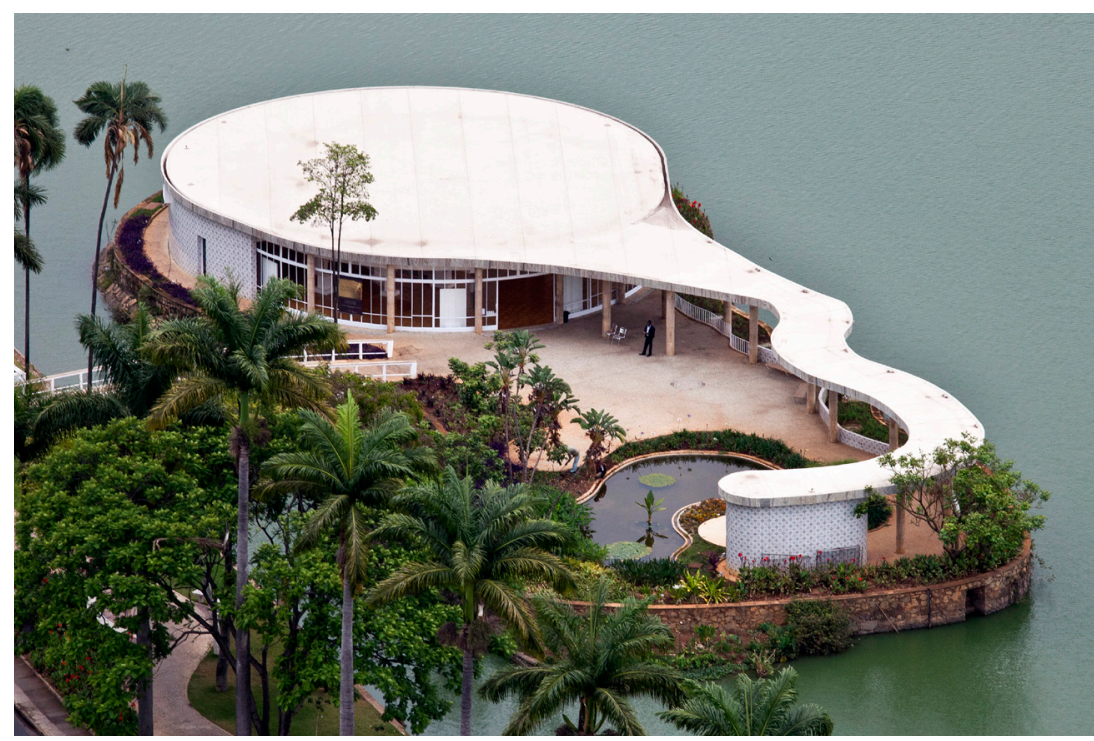

Figura 4 Casa do Baile. Fonte: Marcílio Gazzinelli. 
Figura 5 late Tênis Clube. Fonte: Marcílio Gazzinelli.
3 Órgão federal responsável pela tutela, proteção e promoção de bens culturais de interesse nacional no Brasil.

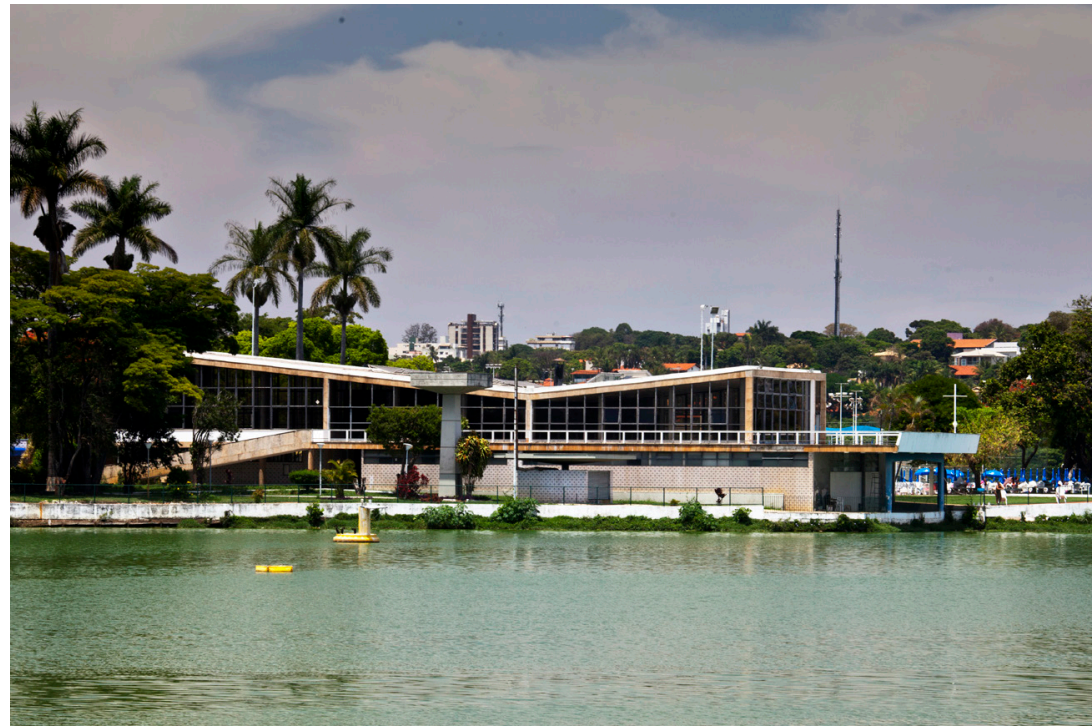

3, 4 e 5). Sua concepção teve a intenção de transmitir uma marca de inovação e vanguarda para a cidade, através da criação de um bairro com aspectos de cidade jardim com residências de alto padrão construtivo em lotes amplos e presença de jardins e maciços verdes, além de equipamentos para lazer, cultura e turismo no entorno do lago existente (IPHAN, 20 I7).

\section{Paisagem Cultural}

A noção de paisagem estabelecida na modernidade é a de um elemento contemplativo. Porém a paisagem não é apenas um cenário para a arquitetura, deve-se respeitar o meio ambiente e considerar o uso sustentável dos recursos naturais acima da estética (Ábalos, 2004). O Conselho da Europa, reconhecendo que a paisagem é um importante elemento da qualidade de vida das populações, constitui um instrumento para promover a proteção, gestão e planejamento das paisagens europeias: a Convenção Europeia da Paisagem (Council of Europe, 2000).

A Paisagem Cultural passa a ser oficialmente reconhecida como categoria específica do patrimônio cultural e protegida por instrumentos normativos pela UNESCO a partir de 1992, quando a Convenção do Patrimônio Cultural adota diretrizes para sua inclusão na Lista de Patrimônio Mundial e define três categorias para as paisagens culturais: paisagens intencionalmente concebidas e criadas pelo homem, paisagens que evoluem organicamente (que se dividem em duas subcategorias, paisagem relíquia e paisagem contínua) e paisagem cultural associativa (UNESCO, 2005a).

No Brasil, o Instituto do Patrimônio Histórico e Artístico Nacional (IPHAN) ${ }^{3}$ chancela em 2009 a categoria de paisagem cultural, apoiando-se na necessidade de um instrumento legal para garantir o valor cultural da paisagem, prevendo a articulação entre poder público, iniciativa privada e sociedade civil para sua gestão compartilhada (IPHAN, 2009).

Figueiredo (2013) aponta que a gestão da paisagem cultural em ambientes de grande complexidade e dinamismo, como as áreas urbanizadas, 
deve ser imbuída da noção de sustentabilidade, ou seja, não impedir as transformações necessárias ao desenvolvimento e orientá-las em prol da preservação do patrimônio.

\section{Paisagem Urbana Histórica}

A definição de paisagem urbana histórica é apresentada em 2005 no Memorando de Viena, reforçando a ideia de conjunto histórico expressa na Recomendação de Nairóbi ${ }^{4}$. Além dos conjuntos de edificações, considerase também todo o contexto natural e construído que os envolve, as expressões sociais atuais e passadas que formam o caráter e a percepção destas áreas na definição do conjunto histórico (UNESCO, 2005b). Esta definição indica a relação entre a evolução social e as formas físicas, demonstrando a necessidade de avaliar as metodologias de conservação e as ferramentas de gestão atuantes para mitigar as intervenções causadas pelas pressões do desenvolvimento (Bandarin \& Oers, 2012). Segundo essa perspectiva, evidencia-se a importância das políticas de planejamento e a complexidade da conservação e da gestão do patrimônio urbano. A gestão das paisagens urbanas históricas é complexa porque compreende vários subconjuntos de patrimônio sujeitos à pressão do desenvolvimento do ambiente urbano e da atuação competitiva dos diversos grupos sociais de interesse (Zancheti \& Carsalade, 2019).

\section{A Gestão do Patrimônio Urbano}

Castriota (2009) identifica três momentos da evolução da gestão do patrimônio urbano diante dos desafios da contemporaneidade, relacionando-os com mudanças nas características dos instrumentos e das estratégias de acautelamento do patrimônio. $\bigcirc$ primeiro momento tem foco na preservação. As políticas de preservação se preocupavam com a proteção de edificações isoladas, na tentativa de limitar a mudança e manter o objeto em sua originalidade. Os agentes envolvidos nas políticas de preservação eram compostos por historiadores e arquitetos. $\bigcirc$ tombamento era o instrumento legal para a proteção de bens excepcionais. O segundo momento é o da conservação. $\bigcirc$ conceito de patrimônio arquitetônico amplia a sua concepção de monumento histórico para conjuntos arquitetônicos, ocupando-se também de seu entorno, ambiência e significado. O olhar para o patrimônio se desloca da visão limitadora da preservação para uma visão mais flexível da conservação, admitindo algumas mudanças e adaptações para abrigar os novos usos. Este novo olhar sobre o patrimônio se estabelece simultaneamente à ideia de patrimônio urbano. $\bigcirc$ terceiro momento é o da gestão do patrimônio e emerge da dificuldade de conservação de áreas urbanas. $\bigcirc$ poder público se depara com a questão econômica para viabilizar a preservação e a conservação, focando na reabilitação dessas áreas. $\bigcirc$ Estado não é mais apenas o agente para impor restrições por meio de normas de controle, mas promotor e parceiro de projetos para as áreas a serem protegidas, articulando atores públicos, privados e a comunidade para participarem deste novo modelo de

4 A Recomendação propõe a proteção de conjuntos históricos urbanos e o seu enquadramento, ressaltando a necessidade de sua adaptação à vida contemporânea, coordenando as políticas de proteção em todos os níveis e o planejamento urbano (UNESCO, 1976). 
gestão (Castriota, 2009).

Os modelos de financiamento baseados apenas em recursos públicos não são mais suficientes, exigindo arranjos múltiplos e inovadores para a sustentabilidade da gestão urbana. A sustentabilidade de sítios urbanos não pode ser baseada apenas no conceito do benefício financeiro. Deve incorporar os benefícios intangíveis oriundos do patrimônio construído para abranger os valores considerados pela população e pelos usuários locais, contribuindo para a preservação de sua identidade e de sua referência cultural (Throsby, 200 I). A conservação e a renovação de áreas urbanas, utilizando infraestruturas existentes e a manutenção de componentes históricos possibilitam a manutenção de seus elementos culturais (Keene, 200 I).

Neste sentido, a abordagem HUL é um instrumento que propõe a inserção de novas práticas para a gestão urbana, objetivando integrar a conservação ao desenvolvimento, considerando as diversas tradições e identidades culturais, reconhecendo e incorporando mudanças no ambiente construído e natural e, ao mesmo tempo, preservando valores através de processos sustentáveis (Bandarin \& Oers, 20I2).

\section{A Abordagem HUL}

A Recomendação da Paisagem Urbana História propõe diretrizes para a salvaguarda de centros urbanos históricos integrando as estratégias de conservação do patrimônio urbano aos objetivos do desenvolvimento sustentável (UNESCO, 20I I). Sugere implantar políticas públicas que valorizem as dinâmicas existentes, integrar instrumentos de planejamento voltados a contextos urbanos mais amplos às ações de conservação e gerenciamento das áreas históricas, incluindo os diversos grupos de interesse nos processos de tomada de decisão (UNESCO, 2019). A Recomendação propõe instrumentos para auxiliar sua implementação sistematizados em quatro categorias: os instrumentos de engajamento da comunidade, os instrumentos de conhecimento e planejamento, os instrumentos reguladores e os instrumentos financeiros (UNESCO, 20 I 6b).

A abordagem HUL demonstra que a gestão da conservação enfrenta a complexidade dos problemas das cidades contemporâneas e sua sustentabilidade depende da manutenção do significado cultural das áreas urbanas. $O$ significado cultural é conformado de acordo com o meio social e está aberto a novas interpretações dos significados de seus atributos. A abordagem aconselha revisitar o significado cultural das áreas urbanas, para acrescentar novos elementos significativos ou mesmo abandonar outros, devendo ser atualizado de acordo com as mudanças físicas e funcionais dessas áreas causados pela apropriação social das áreas urbanas (Zancheti \& Loretto, 2015).

\section{A Paisagem Cultural do Conjunto Moderno da Pampulha}

Devido às suas qualidades como marco fundador da arquitetura moderna no Brasil, à sua repercussão internacional e como resultado da união de esforços federais, estaduais e municipais, o Conjunto Moderno 
Critérios da unesco que fundamentam o valor universal excepcional (vue) do conjunto moderno da pampulha

(i) representar uma obra-prima do gênio criativo humano

(ii) exibir um evidente intercâmbio de valores humanos, ao longo do tempo ou dentro de uma área cultural do mundo, que teve impacto sobre o desenvolvimento da arquitetura e da tecnologia, das artes monumentais, do urbanismo ou do paisagismo

(iv) ser um exemplar excepcional de um tipo de edifício, conjunto arquitetônico ou tecnológico ou paisagem que ilustre (um) estágio(s) significativo(s) da história humana

Elementos e atributos que transmitem o valor universal excepcional (vue) do conjunto moderno da pampulha

\section{Elementos}

\begin{tabular}{|l|l|}
\hline Relação do conjunto com a paisagem & Espelho d'água \\
\hline Relação entre os componentes do conjunto & Orla da Lagoa \\
\hline Componentes - mesma linguagem arquitetônica & Entorno da Lagoa \\
\hline Componentes - usos ligados ao lazer & Mirantes \\
\hline Obra coletiva - contribuição de vários artistas & lgreja de São Francisco de Assis \\
\hline Inovação na arquitetura & Museu de Arte da Pampulha (Cassino) \\
\hline Inovação no paisagismo & late Tênis Clube \\
\hline Inovação no urbanismo & Casa do Baile \\
\hline Inovação tecnológica para o uso do concreto & Jardins dos monumentos \\
\hline Integração da arquitetura com o paisagismo & Paisagem circundante \\
\hline Integração de diferentes linguagens artísticas & Paisagem vergel e horizontalizada \\
\hline
\end{tabular}

da Pampulha recebeu o título de Patrimônio Mundial da UNESCO em 2016 (20I6a). Seu enquadramento na categoria paisagem cultural demanda uma gestão mais complexa e desafiadora do Conjunto, abrangendo não apenas os monumentos e o seu contexto, mas também a proteção e a conservação do entorno e das dinâmicas socioeconômicas. A partir da titulação, o complexo está submetido a um Plano de Gestão e Monitoramento operacionalizado por um Comitê Gestor ${ }^{5}$ que visa garantir a integração das ações das esferas públicas responsáveis por sua gestão e a conciliação das atividades econômicas, turísticas e culturais da região, traduzidas como metas no planejamento municipal.

O reconhecimento VUE do Conjunto pelo Comitê do Patrimônio Mundial se baseia em critérios presentes não apenas nas suas características arquitetônicas e paisagísticas, mas também nos seus valores subjetivos-(Tabela I). $\bigcirc$ grande desafio enfrentado pelos órgãos de gestão é preservar o VUE, seus elementos significativos e seus atributos e, ao mesmo tempo, conciliar sua conservação com as ameaças da pressão da dinâmica imobiliária metropolitana e dos desafios de desenvolvimento socioeconômico da região. Para tanto, torna-se necessário incrementar o diálogo com a população e verificar até que ponto os valores estabelecidos no dossiê de candidatura são compartilhados pela comunidade. A proteção e preservação do Conjunto e sua zona de amortecimento é garantida por diversos instrumentos legais e ações de natureza urbanística, ambiental e de
Tabela 1 VUE do Conjunto Moderno da Pampulha critérios de fundamentação, elementos e atributos. Fonte:

Elaboração dos autores.

5 Formado por representantes das três instâncias de governo com tutela sobre a área (União, Estado e Município), o Comitê Gestor do Conjunto é presidido pelo IPHAN e conta com a participação de diversos órgãos responsáveis por políticas setoriais, entidades da sociedade civil e lideranças da comunidade local. 
proteção do patrimônio atribuídos a vários órgãos públicos nas três esferas de governo. Preocupados com a segmentação da atuação desses órgãos, os gestores articulam revisões no plano de gestão e monitoramento com o objetivo de simplificar o trâmite dos projetos de intervenção entre as três instâncias governamentais para evitar práticas contraditórias entre eles (Carsalade \& Sousa, 2020).

As variáveis relacionadas ao VUE do Conjunto devem ser aferidas periodicamente por meio do reconhecimento público do Conjunto, como recomendado pelo Plano de Gestão e Monitoramento incluindo as condições de fruição dos seus elementos, o espelho d'água, os monumentos, e as condições ambientais do trecho da orla da lagoa que conecta os monumentos, o estado de conservação do conjunto e o controle das ameaças ao contexto paisagístico no entorno e na zona de amortecimento (IPHAN, 20 I7).

\section{METODOLOGIA}

As relações com a comunidade costumam ser complexas e, no caso da Pampulha, que implica o envolvimento de diferentes setores da comunidade, ainda mais. Há interesses locais (daqueles que vivem na Pampulha), interesses coletivos (de outras áreas da cidade) e interesses gerais como os de outras partes do país e do mundo que necessitam ser entendidos e sincronizados. Nessa direção, os trabalhos aos quais se refere este artigo buscam uma metodologia que consiga verificar valores compartilhados como ponto de partida para uma gestão participativa. Assim, esta pesquisa envolve três fases: a fase exploratória, o trabalho de campo e o tratamento do material coletado (Minayo, 2016). Os resultados ora apresentados referem-se à fase exploratória desta pesquisa que parte da revisão bibliográfica sobre Paisagem Urbana Histórica para melhor entender suas especificidades e a importância da participação comunitária em processos de planejamento e gestão de paisagens urbanas de interesse cultural.

Como método de investigação destinado a estabelecer o diálogo com a comunidade acerca do compartilhamento dos valores reconhecidos pelos órgãos de patrimônio, optou-se pela utilização do Conjunto Moderno da Pampulha como estudo de caso. Para tanto, investiu-se na busca e análise de dados e informações secundárias produzidas pelos principais documentos técnicos que compuseram o processo de candidatura do Conjunto Moderno da Pampulha a Patrimônio Mundial, com destaque para o Dossiê e seu respectivo Plano de Gestão e Monitoramento. Ainda nesta fase foi elaborado o instrumento de pesquisa para coleta de dados primários junto à comunidade. Devido à pandemia da Covid 19, a alternativa encontrada para estabelecer o diálogo com os diversos segmentos sociais foi a disponibilização de um questionário em plataforma online de acesso ao público em geral. As questões objetivaram investigar o compartilhamento dos valores que levaram à atribuição do título de Patrimônio Mundial ao Conjunto por diferentes grupos de interesse presentes na área de estudo. 
As questões abertas, as questões de múltipla escolha e as imagens utilizadas no questionário foram objeto de pré-teste aplicado através de link enviado para participantes de três diferentes grupos em três momentos distintos. $\bigcirc$ primeiro grupo, constituído por três entrevistados, focou-se em pessoas com menor nível de escolaridade, buscando verificar a adequação da linguagem para seu fácil entendimento. $\bigcirc$ segundo grupo, composto por doze entrevistados, foi direcionado a especialistas na área do patrimônio, procurando a contribuição destes para o aprimoramento de conceitos e ideias perseguidas pelo questionário. $\bigcirc$ terceiro grupo, composto por um público aleatório e diversificado, teve como foco verificar se as perguntas alcançavam o objetivo esperado pela pesquisadora. Neste grupo o link do questionário foi enviado para alguns contatos que, por sua vez, o enviaram a outras pessoas, sem controle do número de envios, obtendo-se cinquenta e uma respostas. Os contatos do primeiro e do segundo grupo foram monitorados e contatados após responderem ao questionário para apurar suas críticas e sugestões, que contribuíram para o aperfeiçoamento do questionário. Já as respostas do terceiro grupo foram utilizadas para os ajustes finais do questionário e esboço das categorias de análise apresentadas ao final deste artigo, sempre em diálogo com os atributos da UNESCO, objeto de aferição do estudo.

A fase do trabalho de campo da pesquisa coincidiu com a fase mais restritiva imposta pela Covid 19, sendo a versão definitiva do questionário disponibilizada online. Inicialmente, o link do questionário foi divulgado entre a rede diversificada de relacionamento da autora como ponto de partida, adquirindo maior aleatoriedade, abrangência e quantidade de respondentes à medida que um contato envia para outro, ampliando a rede inicial de contatos e o número de possíveis respondentes. Assim como no pré-teste, o tratamento final do material coletado está sendo realizado por meio da abordagem metodológica da pesquisa qualitativa que se apresenta adequada para a investigação e apuração da percepção dos valores reconhecidos pelos respondentes para a paisagem da área de estudo.

Embora os resultados sejam preliminares, a intenção desta primeira pesquisa foi a de testar a metodologia para sua aplicação ampla, sendo esta a intenção básica das reflexões que apresentamos aqui. As principais contribuições do pré-teste para o aperfeiçoamento do questionário foram a redução do número de questões, a simplificação da linguagem, a ampliação do número de questões abertas com exploração dos motivos e justificativas das respostas e a utilização de imagens como estratégia para estimular a percepção dos entrevistados para os elementos significantes e os atributos da paisagem que traduzem o VUE do Conjunto (Figuras 6 e 7 ).

O questionário foi estruturado em quatro partes. A primeira destina-se a caracterizar o perfil do entrevistado; a segunda verifica o relacionamento do entrevistado com a Pampulha (periodicidade de frequência, atividades propiciadas pelo local que o atraem, atributos e elementos da paisagem 
Figura 6 Orla da lagoa da Pampulha. Fonte: Acervo dos autores, 2019.

Figura 7 Fachada posterior da Igreja São Francisco de Assis painel em azulejos de autoria de Cândido Portinari. Fonte: Acervo dos autores, 2019.
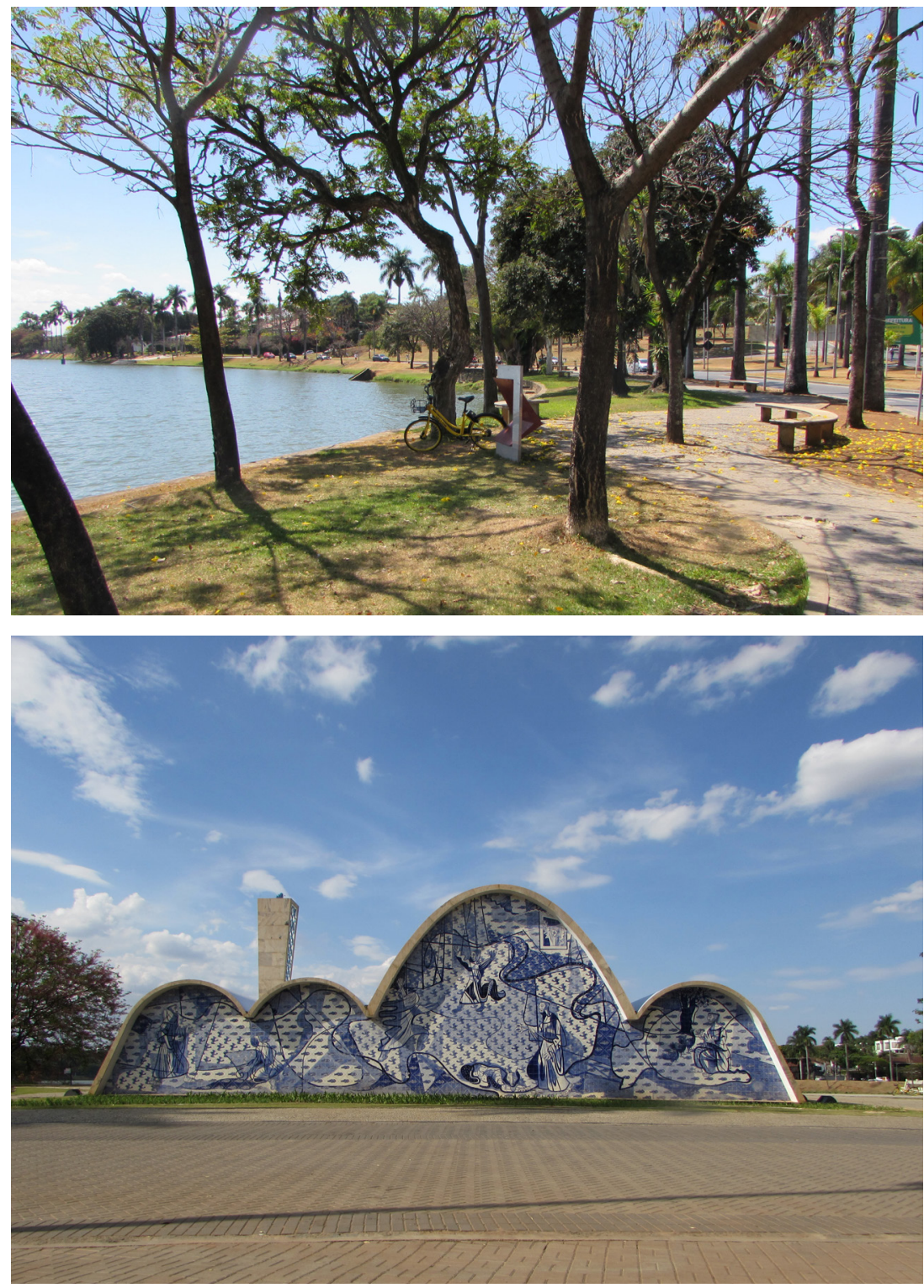

que valoriza); a terceira parte investiga a percepção do Conjunto Moderno da Pampulha pelo entrevistado (elementos que o compõem, avaliação da conservação e do uso dos monumentos, verificação de características e atributos do Conjunto); a quarta parte averigua o conhecimento do entrevistado sobre o título de patrimônio mundial e sobre a razão da sua atribuição.

As categorias definidas inicialmente para a interpretação das respostas do questionário emergiram da análise de conteúdo dos resultados obtidos no pré-teste, entendido como a identificação das diferentes percepções dos respondentes. Estas categorias procuraram contemplar o VUE reconhecido para a paisagem cultural do Conjunto Moderno da Pampulha traduzido em seus elementos e atributos.

A pergunta do tipo múltipla escolha, "O que the chama mais atenção na Pampulha?", apresenta sete elementos da paisagem da Pampulha e o respondente deve escolher apenas uma opção. Em um universo de sessenta 

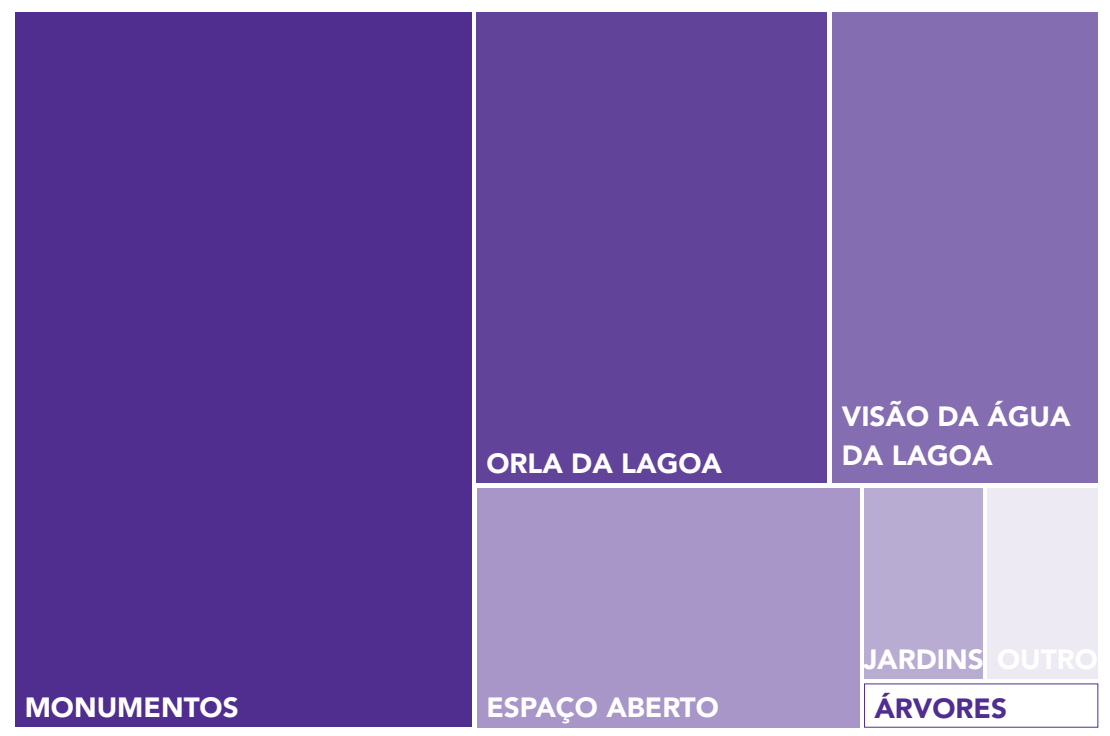

Tabela 2 Elemento da paisagem que mais chama a atenção do entrevistado na Pampulha. Fonte: Elaboração dos autores.

e seis respostas, a opção "os monumentos no entorno da lagoa" corresponde à maior frequência das respostas (42\%). Em seguida vem a opção "a orla da lagoa" com $21 \%$ das respostas, "a visão da água da lagoa" com 17\%,"o espaço aberto" com 12\%, "os jardins das casas" com 3\% e "as árvores" com 2\%. A opção "as casas" não obteve nenhuma resposta. Já a opção "outro" apresentou duas respostas: "todo o conjunto composto dos elementos descritos acima" e "o quanto a região é mais uma "ilha" na desigual configuração do espaço de BH", reforçando o caráter de paisagem diferenciada no contexto da cidade (Tabela 2). As respostas obtidas para esta questão evidenciam o reconhecimento pelos entrevistados de elementos e atributos que transmitem oVUE do Conjunto: a relação do conjunto com a paisagem, a orla da lagoa, o espelho d'água, os monumentos e a paisagem circundante.

Outra pergunta do pré-teste do questionário apresenta um mosaico com fotos dos quatro monumentos que compõem o Conjunto e o seguinte enunciado "O que chama sua atenção nas fotos abaixo?". Dentre as respostas observadas nos três grupos, a maioria se relaciona à categoria arquitetura ou obra-prima, expressa frequentemente pelo termo "beleza". Para a pergunta "O que é a Pampulha para você?', a maioria das respostas se encaixam nas categorias obra-prima, identidade e parque urbano, esta última em referência à paisagem diferenciada do Conjunto no contexto da cidade. Estas respostas confirmam novamente a valorização dos elementos e atributos que transmitem o VUE desta paisagem.

As perguntas "O que você mais gosta na Pampulha?" " "O que você menos gosta na Pampulha?' tiveram o intuito de identificar o atributo da paisagem que o entrevistado mais valoriza e aquele que mais o incomoda, respectivamente. $\mathrm{Na}$ modalidade pergunta aberta, essas perguntas não condicionaram ou sugeriram as respostas, sendo que os elementos e atributos característicos da paisagem foram levantados pelos entrevistados. De acordo com a análise preliminar, para os aspectos positivos, as respostas foram incluídas em três categorias: paisagem, parque urbano e conjunto arquitetônico. A categoria paisagem abrange elementos como a lagoa, sua orla, a natureza, a paisagem vergel e horizontalizada, a amplitude visual, além da percepção da beleza e da integração da arquitetura 
Tabela 3 Atributo da paisagem da Pampulha mais valorizado pelo entrevistado. Fonte: Elaboração dos autores.
Tabela 4 Atributo da paisagem da Pampulha que incomoda o entrevistado. Fonte: Elaboração dos autores.
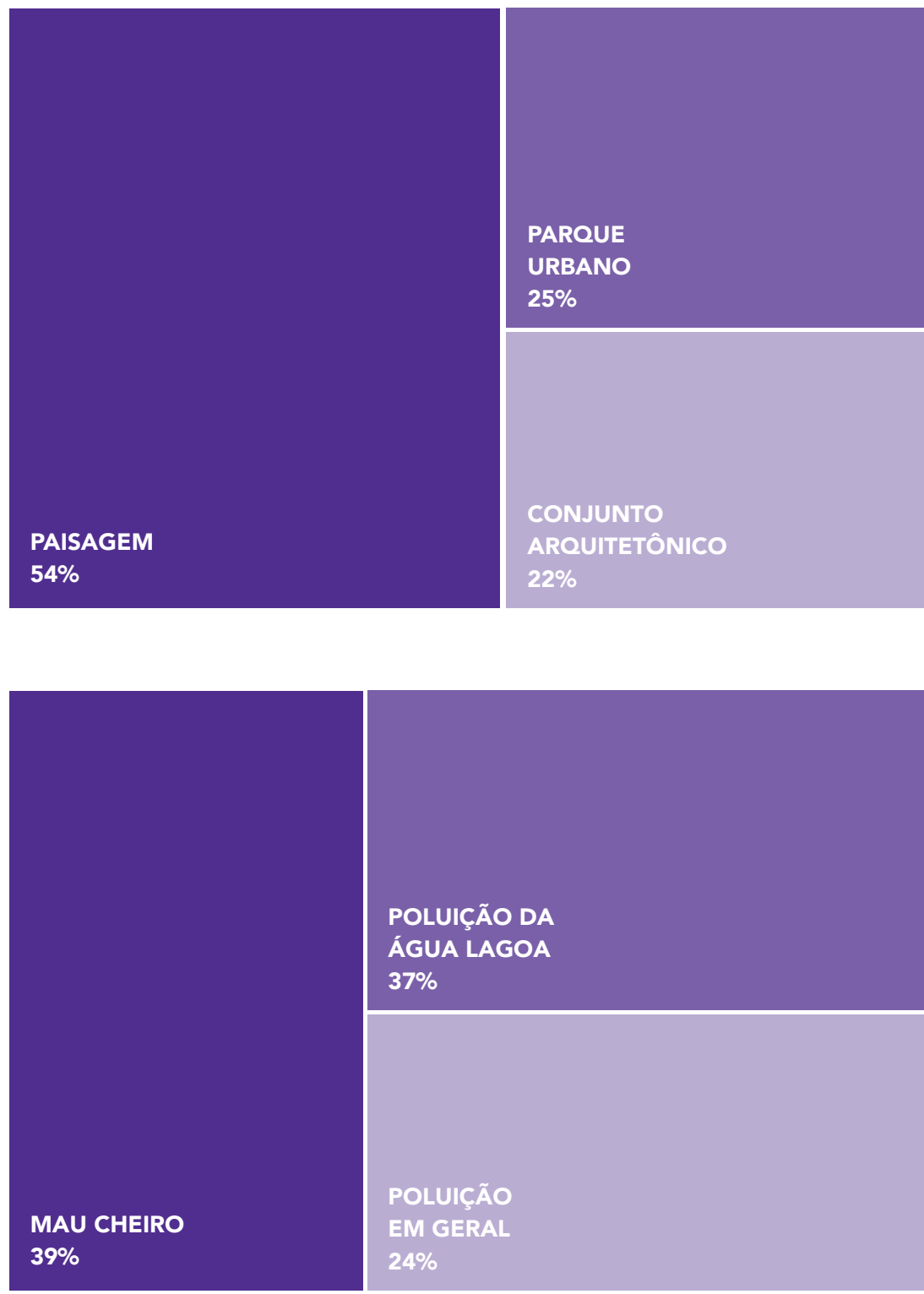

\section{CONJUNTO}

AROUITETONNICO

$22 \%$

com o contexto, compreendendo $54 \%$ das respostas; a categoria parque urbano inclui as respostas que se referem às sensações de bem-estar propiciadas pelas características do local, como as áreas livres, uma área diferenciada no contexto urbano e aos equipamentos urbanos que oferecem condições para o lazer e a prática de esporte, obtendo 25\% das respostas; a categoria conjunto arquitetônico contemplou respostas que enaltecem a arquitetura, os monumentos e o patrimônio, contabilizando 22\% das respostas (Tabela 3).Verifica-se que os elementos da natureza presentes nesta área são muito valorizados pelos entrevistados, assim como as características que a definem como uma área diferenciada no contexto da cidade. No entanto, não apenas a presença da natureza é valorizada pelos entrevistados. Reconhece-se também a presença da arquitetura como elemento que conforma as características desta área urbana e sua integração com o contexto natural.

Para os aspectos da paisagem que incomodam os entrevistados, as respostas foram distribuídas nas categorias: poluição (65\% das respostas), má 
conservação (9\%), tráfego (6\%), carência de infraestrutura (4\%), outros (6\%), não sei (4\%), nada (3\%) e respostas inconsistentes (3\%). Na categoria poluição, $37 \%$ das respostas referem-se diretamente à poluição da água da lagoa e 39\% ao mau cheiro causado pela poluição da água da lagoa, outros $24 \%$ referem-se à poluição em geral (Tabela 4). É interessante constatar que a poluição da lagoa é o fator de maior relevância para a fruição da região e sua solução de grande importância para a população.

A despoluição da água da lagoa é um dos maiores desafios impostos aos gestores do Conjunto Moderno da Pampulha, problema que persiste desde os anos 1980. Anteriormente, o esporte náutico era praticado na lagoa, mas, desde os anos 1980, as águas da lagoa não mais propiciam condições adequadas para esta atividade. Esta situação é oriunda do adensamento urbano na bacia da Pampulha, cuja maior parte situa-se no município vizinho, e a intensificação do adensamento urbano nessa área na última década. A melhoria da qualidade da água da lagoa para permitir a recreação configura-se também como uma das recomendações do ICOMOS ${ }^{6}$ que integra o Dossiê de candidatura do Conjunto (IPHAN, 20I7).

○ questionário utilizado no pré-teste se mostrou eficiente enquanto ferramenta experimental para a análise dos elementos valorados pelos diversos respondentes e para seu aprimoramento.

Este artigo apresentou o método utilizado para a construção da ferramenta para aferição da percepção-pela comunidade do VUE e seus respectivos elementos e atributos nos quais se basearam a declaração de significância cultural do Conjunto Moderno da Pampulha como Patrimônio Mundial. Destacou a etapa de revisão bibliográfica sobre a abordagem HUL e os documentos que embasaram a candidatura com o objetivo de elencar os principais conceitos que referenciam a pesquisa e a análise dos resultados do pré-teste, tanto para o aperfeiçoamento do instrumento utilizado para dialogar com a comunidade, como para a construção de categorias de análise para o tratamento das respostas.

Os grupos de respondentes que participaram desta etapa exploratória da pesquisa contemplaram diferentes níveis de escolaridade e profissões, moradores de várias regiões da cidade e da região metropolitana, apresentando uma amostragem dos diversos grupos de interesse na área de estudo. A relação do conjunto com a paisagem, o uso ligado ao lazer e à prática de esporte, a orla da lagoa, o espelho d'água, o entorno da lagoa, a paisagem vergel e horizontalizada, os jardins, assim como a arquitetura e a beleza são algumas das características da região destacadas pelos entrevistados nesta fase. Ainda que não sejam características diretamente ligadas aos valores dos edifícios e elementos artísticos a eles associados, constituem elementos e atributos que transmitem o VUE do Conjunto como paisagem cultural, os quais devem ser preservados e monitorados pelos gestores para a manutenção do título de patrimônio mundial. Valores que preservados podem contribuir para a manutenção de suas características de paisagem diferenciada no contexto da cidade. A amostragem das respostas do questionário tende a confirmar que a

6 O ICOMOS, Conselho Internacional de Monumentos e Sítios, é uma organização não governamental associada à UNESCO, que tem como objetivo promover a conservação, a proteção, o uso e a valorização de monumentos, centros urbanos e sítios. 
população valoriza a relação entre os monumentos, os jardins, a lagoa, sua orla e os maciços arbóreos com todo o ambiente construído e os seus usos, o que os tornam indissociáveis deste contexto.

Devido às circunstâncias de distanciamento social impostas no ápice da manifestação da Covid 19 quando a pesquisa de campo foi realizada, a maneira encontrada para escutar a comunidade, e contribuir para o cumprimento da exigência de envolvimento da comunidade contida no plano de gestão, foi mediante o questionário online. $\bigcirc$ recurso encontrado, apesar de não ser o ideal, se apresentou como alternativa satisfatória para restabelecer o diálogo com a comunidade, divulgar o reconhecimento do Conjunto como patrimônio mundial e a importância de sua conservação para a manutenção de um importante elemento da identidade da cidade.

Verificou-se que mais do que valores universais excepcionais, são os elementos e os atributos presentes na paisagem do Conjunto Moderno da Pampulha que contribuem para a materialização de tais valores como paisagem cultural e que se anunciam como aspectos reconhecidos e valorizados pelos diversos grupos de interesse na área. Estas conclusões se tornaram importantes para aferir os meios e modos de ouvir a comunidade envolvida e acertar os modos de sua participação.

\section{AGRADECIMENTOS}

Agradecimento à CAPES pela bolsa concedida no mestrado do Programa de Pós-Graduação em Ambiente Construído e Patrimônio Sustentável da UFMG possibilitando o desenvolvimento da pesquisa.

\section{REFERÊNCIAS BIBLIOGRÁFICAS}

Ábalos, I. (2004). O que é a paisagem? Arquitextos Vitruvius, (05), 049.00. https:// vitruvius.com.br/revistas/read/arquitextos/05.049/572/pt

Bandarin, F., Oers, R. v. (2012). The historic urban landscape: managing heritage in an urban century. Wiley Blackwell.

Carsalade, F. L. \& Sousa, M. L. M. A. (2020). Conjunto Moderno da Pampulha: evolução da sua gestão desde a sua candidatura a patrimônio mundial da humanidade. In: Amoroso, M. R., Guimaraens, C., Dias, D., Costa, A. \& Tavares, A. (Orgs.). Patrimônio Arquitetônico Brasil - Portugal. (pp. 129-I 38). Proarq; Universidade de Aveiro. https://www.academia.edu/44054882/Patrim\%C3\%B4nio_ Arquitet\%C3\%B4nico_Brasil_Portugal.

Castriota, L. B. (2009). Patrimônio cultural: conceitos, políticas, instrumentos. Annablume; IEDS.

Council of Europe (2000). European Landscape Convention. European Treaty Series No. 176. Florence: Council of Europe. https://rm.coe.int/I 68008062 I

Figueiredo, V. G. B. (20 I 3). O patrimônio e as paisagens: novos conceitos para velhas concepções? Paisagem e Ambiente, (32), 83- I I 8. https://doi.org/ I 0. I I 606/issn.2359536।.v0i32p83-118

INSTITUTO DO PATRIMÔNIO HISTÓRICO E ARTÍSTICO NACIONAL (2009). Portaria n. 127 de 30 de abril 2009. Estabelece a chancela da Paisagem Cultural Brasileira. Brasília: IPHAN. https://www.normasbrasil.com.br/norma/ portaria-127-2009_21427|.html 
INSTITUTO DO PATRIMÔNIO HISTÓRICO EARTÍSTICO NACIONAL (20 I7). Dossiê de candidatura do Conjunto Moderno da Pampulha para inclusão na lista do patrimônio mundial da UNESCO. Brasilia: IPHAN.

Keene, J. (200I).The links between historic preservation and sustainability: an urbanist's perspective. In:Teutonico, J. M. \& Matero, F. (Orgs.). Managing change: sustainable approaches to the conservation of the built environment. (pp. I I-19). The Getty Conservation Institute. https://www.getty.edu/conservation/publications_ resources/pdf_publications/pdf/managing_change_vl_opt.pdf

Minayo, M.C.S. (2016). O desafio da pesquisa social. In: Gomes, R., Deslandes, S. F. \& Minayo, M.C.S. (Orgs.). Pesquisa social: teoria, método e criatividade (Cap. I, pp. 9-28). Editora Vozes.

Throsby, D. (200 I). Sustainability in the conservation of the built environment: an economist's perspective. In: Teutonico, J. M. \& Matero, F. (Orgs.). Managing change: sustainable approaches to the conservation of the built environment. (pp. 3-10). The Getty Conservation Institute. https:/www.getty.edu/conservation/publications_ resources/pdf_publications/pdf/managing_change_vl_opt.pdf.

UNESCO (1976). Recomendação sobre a salvaguarda dos conjuntos históricos e da sua função na vida contemporânea. Nairobi: UNESCO. http://www. patrimoniocultural.gov.pt/media/uploads/cc/salvaguardaconjuntoshistoricos 1976.pdf

UNESCO World Heritage Centre (2005a). Operational guidelines for the implementation of the World Heritage Convention. Paris: UNESCO World Heritage Centre. http://whc.unesco.org/archive/opguide05-en.pdf

UNESCO World Heritage Centre (2005b). Vienna memorandum on world heritage and contemporary architecture: managing the historic urban landscape. Paris: UNESCO World Heritage Centre. https://whc.unesco.org/archive/2005/whc05- I5ga-inf7e.pdf

UNESCO World Heritage Centre (20I I). Recommendation on the Historic Urban Landscape, including a glossary of definitions. Paris: UNESCO World Heritage Centre. https:/whc.unesco.org/uploads/activities/documents/activity-638-98.pdf

UNESCO World Heritage Centre (20 I6a). Nominations to the World Heritage List. Paris: UNESCO World Heritage Centre, pp. 38-4I. https://whc.unesco.org/ archive/20I 6/whcl 6-40com-8B-en.pdf

UNESCO World Heritage Centre (20 I6b). The HUL guidebook: managing heritage in dynamic and constantly changing urban environments: a practical guide to UNESCO's Recommendation on the Historic Urban Landscape. [Paris]: [UNESCO]. https:// gohulsite.files.wordpress.com/2016/10/wirey5prpznidqx.pdf

UNESCO World Heritage Centre (2019). The UNESCO Recommendation on the Historic Urban Landscape: report of the second consultation on its implementation by member states. Paris: UNESCO World Heritage Centre. http://whc.unesco.org/en/ activities/638

Zancheti, S. M. \& Loretto, R. P. (2015) Dynamic integrity: a concept to historic urban landscape. Journal of Cultural Heritage Management and Sustainable Development, 5(I), p. 82-94. https://doi-org.ez27.periodicos.capes.gov.br/ / 0.1 I 08 / JCHMSD-03-20 I 4-0009

Zancheti, S. M. \& Carsalade, F. L. (2019). Conjunto Moderno da Pampulha: patrimônio, gestão turística e desenvolvimento social. Relatório final da jornada especial de trabalho. [Belo Horizonte]: [ICOMOS]. 